\title{
Hydrophobins: Exceptional proteins for many applications in brewery environment and other bio-industries
}

\author{
M. Khalesi*, S.M. Deckers, K. Gebruers, L. Vissers, H. Verachtert, G. Derdelinckx \\ KULeuven-FBIW-M²S-LIBR (Leuven Institute for Beer Research) - site MbS, Kasteelpark Arenberg, 33 PO Box 2463 B-3001, Heverlee, Belgium
}

\section{A R T I C L E I N F O}

\section{Keywords:}

Hydrophobin

Application

Biosurfactant

Self-assembly

Immobilization

\begin{abstract}
A B S T R A C T
Hydrophobins are exceptional proteins produced by fungi. Research over the last decade has led to a better understanding of their role in spontaneous self-assembly at hydrophobic/hydrophilic interfaces. This has resulted in many proposals for using hydrophobins in many important scientific and technological applications. Hydrophobins may become attractive as special biosurfactants, as foaming agents and for protein immobilization in the food industries and in biosensors. Moreover, they can be interesting as stabilizers for flavors, and as, encapsulating agents of trace ingredients in beverages. The use of hydrophobins in pharmaceutical formulations and in medicine is another interesting application as they cause an increased stabilization of drugs. The study of hydrophobins must also lead to a better understanding of the gushing phenomenon in beverages like beers, wines and ciders, which causes great economic losses in those fields. To recognize the positive and the negative aspects of hydrophobins these proteins should be commercially available at large scale which however is not the case. An overview of existing possibilities for applications may help to understand their behavior in different environmental conditions and to stimulate finding improved methods for isolation and purification, and possibly other unexpected applications.
\end{abstract}

(c) 2012 the Associations of the Former Students of the Belgian Brewing Schools. Published by Elsevier B.V. All rights reserved.

\section{Introduction}

Hydrophobins are a large family of small cysteine rich proteins (about 100 amino acids) (Chaplin and Kennedy, 1994) with a molecular mass of around $10 \mathrm{kDa}$ (Cooper and Kennedy, 2010) (Fig. 1). The name hydrophobin was originally used due to their high content of hydrophobic amino acids (Armenante, 2008). The proteins are secreted by fungi into liquid media or remain at the surface of aerial mycelia (Stubner et al., 2010). Recent evidence demonstrates that a broad spectrum of functions in fungal growth and development is mediated by hydrophobins (Armenante, 2008). They have been detected in fungal plant pathogens (Talbot et al., 1996; Bidochka et al., 2001), insect pathogens (St Leger et al., 1992), and human pathogens (Parta et al., 1994) and saprophytes (BellPedersen et al., 1996). More than one type of hydrophobin has been found in most moulds. For example, in Schizophyllum commune, at least four hydrophobin-encoding genes (Sc1-Sc4) with dissimilar functions have been isolated (Wessels, 1993). Due to the distribution of the cysteines and the clustering of hydrophobic and hydrophilic residues, hydrophobins are divided into two classes:

\footnotetext{
* Corresponding author. Tel.: +32 16 321461; fax: +32 16321997.

E-mail address: mohammadreza.khalesi@biw.kuleuven.be (M. Khalesi).
}

class I such as SC3 and EAS, and class II like HFBI and HFBII. The aggregates formed by both classes are distinguished on the basis of their solubility and morphology (Linder, 2009a, b).

Hydrophobins can assemble at a hydrophilic-hydrophobic interface forming an amphipathic film (Wessels, 2000) (Fig. 2). This film makes hydrophobic surfaces of liquid or solid materials wettable, while hydrophilic surfaces are becoming hydrophobic. Thanks to their extraordinary properties, hydrophobins were consequently first suggested for a number of applications involving the modification of surfaces properties (Janssen et al., 2002a, b) leading to improving biocompatibility, reducing friction, or providing specific sites for protein immobilization (Kisko, 2008) (Table 1). The self-assembly of hydrophobins (Wösten and Wessels, 1997) is interesting in the field of surfactants, emulsifiers, and surface coating. Using the hydrophobin in future nanotechnology applications (e.g. patterning molecules at a surface with nanometer accuracy) (Scholtmeijer et al., 2001; Wang et al., 2004; Thomas, 1995), may lead to improving biosensors (Bilewicz et al., 2001), and applications in tissue engineering (Lumsdon et al., 2005). Remarkable is the possibility to separate and isolate nutritional proteins of interest by fusing them to the hydrophobins. This could result in a generic, rapid and efficient protein purification system (Linder et al., 2004). As hydrophobins are adsorbed easily to both hydrophilic and hydrophobic surfaces, such as glass, mica, parafilm, and Teflon, 


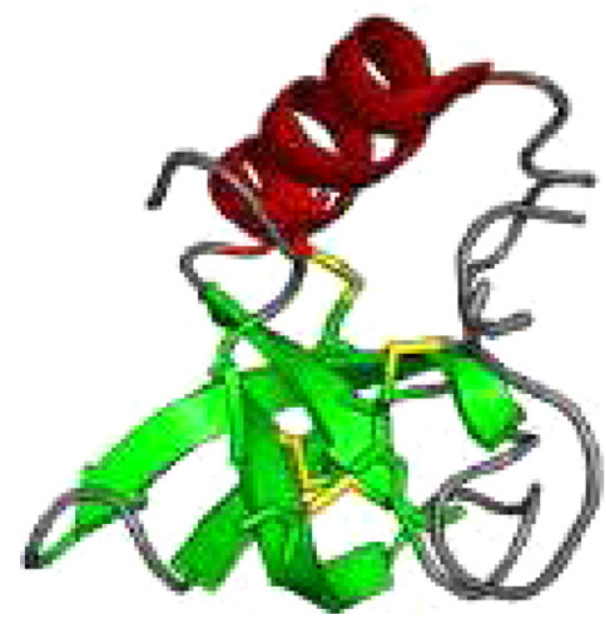

Fig. 1. Structure of hydrophobin HFBII (Armenante, 2008). Cartoon of the protein backbone structure showing the $\beta$-barrel formed by two $\beta$-hairpins (green) and the connecting $\alpha$-helix (red). The disulfide bonds of Cys residues are shown in yellow. (For interpretation of the references to color in this figure legend, the reader is referred to the web version of this article.)

resulting in modification of their properties (Wösten et al., 1994) and the ability of hydrophobins to assemble into strong monolayers and to modify the hydrophobicity of a surface these proteins may have a wide range of potential usages as biotechnological tools (Mackay et al., 2001). Increasing demands for hydrophobins leads to a challenge in terms of the production and purification of this product (Subkowski et al., 2007; Winterburn et al., 2011a, b).

For the stabilization of oil vesicles, or oil emulsions, in pharmaceutical applications hydrophobins might be used instead of traditional surfactants (Scholtmeijer et al., 2001). Hydrophobins with suitable properties are potential candidates for native biosurfactants to treat repellency. On the other hand, understanding their involvement in modification of hydrophobicity could open up new applications, for instance in using fungal field inoculants (Rillig, 2005). The amphiphilic nature of hydrophobins can also be exploited using its surfactant-like behavior in solutions, since they are quite soluble in water (Lahtinen et al., 2008). Recently, the
Table 1

Some different applications of hydrophobin.

\begin{tabular}{|c|c|c|}
\hline $\begin{array}{l}\text { Type of } \\
\text { hydrophobin }\end{array}$ & Application & References \\
\hline Class I SC3 & Teflon surface modification & Scholtmeijer et al. (2002) \\
\hline Class II HFBI & $\begin{array}{l}\text { A potential fusion partner for } \\
\text { one-step purification of avidin } \\
\text { from insect cells }\end{array}$ & Lahtinen et al. (2008) \\
\hline Class II HFBI & $\begin{array}{l}\text { Efficient purification of } \\
\text { endoglucanase I }\end{array}$ & Linder et al. (2004) \\
\hline Class I SC3 & $\begin{array}{l}\text { Formulation of water insoluble } \\
\text { drugs for oral administration }\end{array}$ & Akanbi et al. (2010) \\
\hline Class II HFBI & Coating of drug nanoparticle & Valo et al. (2010) \\
\hline Class I SC3 & Polymer surface modification & Misra et al. (2006) \\
\hline Class I SC3 & $\begin{array}{l}\text { Immobilization of glucose } \\
\text { oxidase and horseradish } \\
\text { peroxidase }\end{array}$ & Corvis et al. (2005) \\
\hline Class II HFBI & Glass surface modification & Qin et al. (2007a, b) \\
\hline $\begin{array}{l}\text { Class I SC3 and } \\
\text { SC4 }\end{array}$ & Surface modification & Janssen et al. (2002a, b) \\
\hline Class I HGFI & $\begin{array}{l}\text { To disperse multi-walled } \\
\text { carbon nanotubes (MWCNTs) }\end{array}$ & Wang et al. (2010a, b, c) \\
\hline Class I SC3 & RGD modified polymer & Hersel et al. (2003) \\
\hline Class II HFBII & $\begin{array}{l}\text { Stabilization of bubbles and } \\
\text { foams }\end{array}$ & Basheva et al. (2011) \\
\hline
\end{tabular}

ability of hydrophobins to increase the dispersion of hydrophobic particles in water has been described (Wang et al., 2010a, b, c).

Although various applications are expected for native hydrophobins, the modification of hydrophobin structures might offer more possibilities as it may lead to changing the biophysical properties of the hydrophobin surface. By changing the surface hydrophobicity, the binding of various molecules and cells can be manipulated (Hektor and Scholtmeijer, 2005). The self-assembly at hydrophobic/hydrophilic interfaces as well as the nontoxic nature of hydrophobins allow them to be introduced into a number of products (Kershaw and Talbot, 1998). A negative aspect of hydrophobins is that they are produced by fungi when growing on grains (e.g. barley) and during grain treatment. Barley is a very important vegetal food with high economic value as it is used in the production of beer and other drinks (Ehrenbergerova et al., 2006; Jood and Singh, 2001; Sehgal and Kawatra, 1998). The presence of hydrophobins leads to gushing, which has many economic

\section{- Hydrophobin monomers \\ Mn Assembled hydrophobin}

A
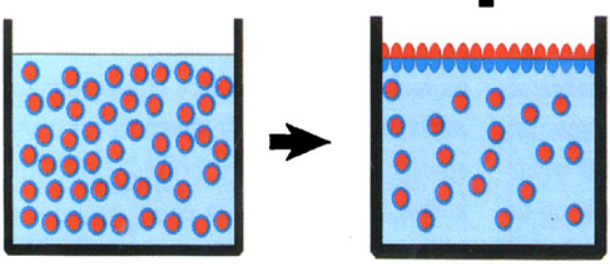

C
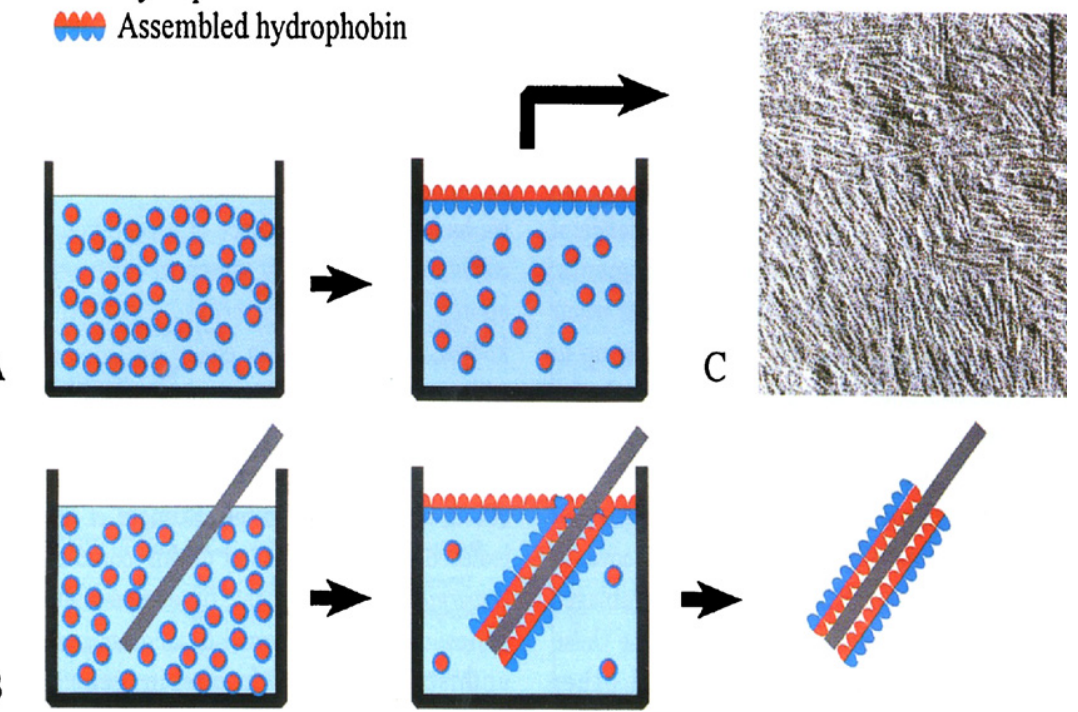

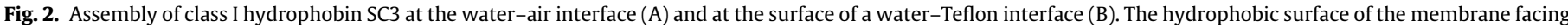

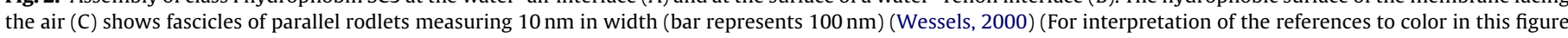
legend, the reader is referred to the web version of this article.). 
drawbacks for brewing industries. Consequently, improvement in rapid and early detection methods for hydrophobins is required (Shokribousjein et al., 2011).

The aim of this report is to emphasize the different applications of hydrophobins and to stimulate more studies for finding methods to detect, isolate and produce these valuable proteins.

\section{Hydrophobins: novel biosurfactants}

Finding harmless surface active components is a challenging topic in food industries and hydrophobins have become outstanding candidates in that context (Murray et al., 2009). These unusual proteins seem to adsorb and act as rigid hydrophobic nanoparticles.

Hydrophobins are surfactive molecules that can polymerize at an air/water or water/oil interface and therefore, form a strong, polymeric monolayer which can reverse the hydropathicity of surfaces (Mackay et al., 2001). Their surface activity is at least similar to that of traditional biosurfactants, such as glycolipids, lipopeptides/lipoproteins, phospholipids, neutral lipids, substituted fatty acids, and lipopolysaccharides and thus hydrophobins can be applied as an alternative in different branches of industry (e.g. in emulsions and dispersions) (Scholtmeijer et al., 2001). Despite having properties of usual surfactants, the surface activity of hydrophobins is not due to a lipid-like partial structure, but to the presence of particular amino acids in a specific sequence (Scholtmeijer et al., 2001).

Analysis of the S. commune SC3, and the T. reesei hydrophobins HFBI and HFBII show that these hydrophobins can stabilize oil droplets but the effects concerning the size of droplets and their stability are different (Linder et al., 2005). Wang and his co-workers (Wang, 2004) show that the class I hydrophobin SC3 forms a membrane when it is assembled on water/oil interfaces at high concentrations (above $50 \mu \mathrm{g} / \mathrm{mL}$ ). This membrane allows unidirectional passage of small molecules of up to $10,000 \mathrm{Da}$ in size from the hydrophobic to the hydrophilic side but prevents the passage of molecules ranging from 300 to 10,000 Da from the hydrophilic side. Another notable phenomenon is that addition of SC3 to a planar lipid bilayer system appears to cause voltage independent pore formation, as determined by the release of calcein (Wang, 2004). SC3 has an influence on DOPC/DOPE (dioleoylphosphatidylcholine/dioleoylphosphatidylethanolamine) liposomes but does not destabilize DPPC (dipalmytoylphosphatidylcholine) liposome. Other proposed applications include the use of hydrophobins as emulgators in food processing, liposome applications and oil refining.

As mentioned earlier, hydrophobins can stabilize air-filled emulsions in foods (Tchuenbou-Magaia et al., 2009), and these emulsions have been used to create a tri-phasic emulsion system with up to $30 \%$ air phase and $30 \%$ oil phase stabilized with Tween 60 . The tri-phasic emulsions were physically stable with little or no coalescence or ripening of either emulsion phase over 45 days.

Recombinant hydrophobins can modify hydrophilic and hydrophobic surfaces (glass and Teflon, respectively) for different applications in food industries (Schmoll et al., 2010). From such observations and due to a recent patent by Guzmann et al. (2009) more applications for hydrophobins are expected for long terms stabilization of different phases in food products.

\section{Hydrophobins in foam stabilization and gushing}

The presence of hydrophobins causes foaming in shaken microbial cultures due to their surface activity. In particular, aerated bioreactor cultures of filamentous fungi often suffer from foaming, and antifoam agents are needed (Linder et al., 2005). The mechanism of foam stabilization by hydrophobins may result in high surface elasticity. Bailey et al. (2002) have studied the problem using $T$. reesei strains in which the $h f b 1$ or $h f b 2$ genes were either inactivated or overexpressed. Overexpression of the hydrophobins led to increased foaming whereas deletion of the $h f b 2$ gene showed a significant reduction. Other similar studies have demonstrated that bubbles and foams can be stabilized by hydrophobins (Murray, 2007). Also in the hydrophobin-stabilized foam, no disproportionation of the bubbles was observed. This is attributed to the rheology of the surfaces (Stevenson, 2010). Thus, the high surface elasticity of HFBII could stabilize single bubbles against disproportionation for long periods of time, when compared to both $\beta$-casein and $\beta$-lactoglobulin. HFBII forms bubbles stable for 4 days at room temperature. These data confirm the potential of hydrophobins to form stable bubbles and formulate new foam products (Cox et al., 2009).

The exceptional stabilization of aqueous foams with hydrophobin HFBII, at a concentration of $0.1 \mathrm{wt} \%$ protein within a broad range of $\mathrm{pH}$ was also demonstrated by Cox et al. (2009). They reported that when thickening agents are present to lower the rate of creaming, hydrophobin could stabilize foams to some extent. In this case little or no air phase loss was observed for over four months. In addition, they mentioned an example where most of the air phase volume was unchanged even after 2.5 years storage at chill temperature. Although more evidence is needed to completely understand the surface behavior of hydrophobins, it seems that HFBII may act as a nature-designed Janus-like (two phases) particle, adsorbing strongly to the air/water surface, and effectively resisting surface changes in consequence of disproportionation. This is absolutely not the case for milk proteins, which display a relatively low elasticity and have quite insignificant effects on lowering the rate of disproportionation. To fully understand its effects and further exploit its potential, a detailed model for the physical properties of hydrophobin at surfaces and interfaces remains however required.

Although the stabilization of foam by hydrophobin has important positive applications (Talbot et al., 2001), hydrophobins may become a significant problem in the field of beer brewing and the production of sparkling wines and ciders. When a high amount of hydrophobins is present in carbonated beverages, they induce what is known as gushing of the beverages (Linder, 2009a, b; Kleemola et al., 2001). Gushing products cannot be brought on the market and lead to high economic losses and product brand image damages. Some small peptides which consist of hydrophobic amino acids were initially defined as gushing factors (Amaha et al., 1973). Several methods have since been developed to trace the specific presence of the gushing factors either on barley, during intermediate production steps and finally in the final products such as beer (Hippeli and Elstner, 2002). Specific methods for detection and/or identification of hydrophobins are either immunological methods or based on using the MALDI-TOF-MS technique (matrix-assisted laser desorption ionization time-offlight mass spectroscopy) (Deckers et al., 2010; Sarlin et al., 2005, 2007). Other approaches are based on the observation whether gushing is observed or not in sparkling water on addition of a suspected sample.

Zapf et al. (2006) cloned hydrophobin genes from Fusarium culmorum. They suggested that class II hydrophobins are mainly responsible for gushing in beers. The insolubility of the aggregates from class I hydrophobin may be the reason that these do not participate in the gushing phenomenon.

\section{Hydrophobins in protein immobilization and separation}

Based on the efficient assembly, hydrophobins are used as a tag to purify proteins from complex mixtures. Protein immobilization is an interesting topic in food and nutrition science (Wösten, 2001). 
The captured proteins might be enzymes or nutrient ingredients. In principle, both class I and class II hydrophobins can be used to immobilize proteins, however, class I hydrophobins are preferred when detergents or pressure are involved.

Class I hydrophobin from Pleurotus ostreatus was used to coat material in the micromachining process of crystalline silicon based on potassium hydroxide $(\mathrm{KOH})$, which is of straightforward interest to the microelectronics industry (de Stefano et al., 2007; Janssen et al., 2004). The assembly of the $S$. commune class I hydrophobins SC3 and SC4 on Teflon was studied by Janssen et al. (2004). Changes in conditions for coating were addressed and it was observed that at high temperatures $\left(80^{\circ} \mathrm{C}\right)$, more hydrophobins could be attached than at room temperature. It was shown that the $\beta$-sheet end state of the SC3 and SC4 hydrophobins improves growth of fibroblasts similarly to that observed with the intermediate $\alpha$-helical conformation (Janssen et al., 2004). Similar to the immobilization of enzymes, the immobilization onto columns or other solid supports of proteins such as antibodies, using hydrophobin fusions is predicted. Palomo et al. (2003) used hydrophobins to create protein-protein interaction columns. Firstly, they bound the $P$. ostreatus mycelium-bound hydrophobins on hydrophilic glyoxylagarose. Thereafter, they studied the immobilization of lipases to the column. The authors suggested that the mechanism of lipase immobilization on hydrophobins occurs similarly as immobilization to other hydrophobic carriers.

Liquid-liquid extractions using aqueous two-phase systems (ATPS) are used to purify proteins at large scale. This method is frequently used for purification of membrane proteins (Collen et al., 2002a). The purification efficiency depends on the properties of other proteins in the mixture. Class II hydrophobins display high separation behavior in ATPS. A protein of interest can then be fused to the hydrophobin based on its affinity, resulting in a generic, rapid and efficient purification system (Collen et al., 2002a, b, c). Both $T$. reesei HFBI and HFBII, but in particular HFBI, can be directed to the non-ionic surfactant phase when an aqueous solution containing hydrophobin is mixed with technical grade (e.g. Berol (C11EO2)) or homogenous non-ionic surfactants with different length of hydrophilic head-groups (Linder et al., 2001). Based on ATPS, HFBI could be used as a tag to purify the cellulose endoglucanase I (EGI) and the cellulose-binding domains from the cellobiohydrolases CBHI and CBHII (Bilewicz et al., 2001). A similar approach was followed to purify proteins from insects and plant extracts (Joensuu et al., 2010).

Fusion proteins of the target protein facilitate different characteristics. It often improves the solubility of the target protein and sometimes results in high level expression of the target protein. Efficient separation in ATPS can be used for the selective purification of recombinant protein-hydrophobin fusions. Good production yields of HFBI fusion proteins (e.g. gram per liter) were obtained by using $T$. reesei and the fusion proteins were efficiently separated into the ATPS surfactant phase (Bilewicz et al., 2001; Bordier, 1981; Collen et al., 2002a, b, c). The experiments carried out with homogenous surfactants suggest that there exists a significant relationship between the size of the fusion partner, the composition of the surfactant and the partitioning of the fusion protein (Bilewicz et al., 2001). An ATPS separation of the EGIcore-HFBI fusion product has also been successfully carried out at pilot scale (Selber et al., 2004), showing the industrial potential of the system. Fusion of the goal protein to HFBI thus provides a cheap, easy and efficient way to purify the protein in ATPS and this approach could be applicable for many other proteins. In a recent study, the feasibility and scale-up possibility of extraction in detergent-based ATPS for protein separation from culture broths is demonstrated (Selber et al., 2004).

Grifola frondosa hydrophobin HGFI was used to disperse multiwalled carbon nanotubes (MWCNTs) in water (Wang et al., 2010a, b, c; Callegari et al., 2004). The results suggest that HGFI might non-covalently bind to MWCNTs through hydrophobic interaction.

Since class I hydrophobins may form highly insoluble assemblages, they have not been used as a tag for ATPS purification so far.

Immobilization of flavor compounds by use of natural hydrophobins can be another interesting aspect of this protein in order to keep the aroma in food and beverages without any significant changes for a long time. However, in the latter case, as the gushing phenomenon should be controlled, it is not logical to add this component to carbonated beverages.

\section{Hydrophobins for biosensors improvement}

Although biosensors are used to detect and/or to determine many compounds, such as food ingredients, or several other phenomena, it appears that biosensors with more sensitivity and more accuracy are needed.

A general problem of biosensors using immobilized enzymes is the denaturation of the proteins bound on surfaces (Chakarova and Carlson, 2004). It has been confirmed that a hydrophobin coating can inhibit denaturation of immobilized enzymes and preserve long time activity. Enzymes can be immobilized either covalently (Linder et al., 2002) or non-covalently (Corvis et al., 2005) on a hydrophobin coating as a fusion protein. Recently, a novel non-covalent approach was developed for the functionalization of multi-wall carbon nanotubes (MWNTs) by using HFBI (Wang et al., 2010a, b, c). Due to the amphipathic nature, HFBI could be bound onto the surface of MWNTs to form HFBI-MWNTs nanocomposites with proper dispersion in water. The authors reported that the developed biosensor displays high sensitivity, wide linear range, low detection limit, and fast response for glucose detection, which implicated that the HFBI-MWNTs nanocomposite film holds great promise in designing electrochemical devices. A convenient approach to achieve a stable hydrophilic surface by modifying $\operatorname{poly}(\varepsilon$-caprolactone) (PCL), which is a synthetic biodegradable polymer, with a class II hydrophobin (HFBI) coating was also developed (Wang et al., 2011). HFBI modification converts the surfaces of nonwoven PCL grafts from hydrophobic to hydrophilic, and improves their cyto-compatibility and hemocompatibility. Several types of proteins such as the glucose oxidase from Aspergillus niger, bovine serum albumin, chicken egg avidin and monoclonal IgG1 could adsorb onto a hydrophobic solid that was coated with the class I hydrophobin HGFI and class II hydrophobin HFBI (Qin et al., 2007a, b; Wang et al., 2010a, b, c). Adsorption efficiency of these proteins on hydrophobin layers depends on $\mathrm{pH}$ and ionic strength. Apparently, surface adhesion is due to selective charge interactions. Thus, hydrophobins can transform a non-polar surface into a polar one, and then recruit proteins using charge interactions (Wang et al., 2010a, b, c). This principle has been used to immobilize enzymes in developing biosensors (Corvis et al., 2005; Hou et al., 2009). Zhao et al. (2007) reported that HFBI could be easily adsorbed onto polished platinum electrodes and thereafter used to adsorb glucose oxidase.

The controlled molecular modification of surfaces is a key in the preparation of function-oriented micro-patterned advanced materials. Researchers suggest that hydrophobin coating might be an intermediate to attach cells, proteins, or other type of molecules to hydrophobic surfaces in biosensors. Bilewicz et al. (2001) have studied the assembly of Pisolithus tinctorius hydrophobins HYDPt-1 on electrodes. The hydrophobin-coated electrodes were functionalized with electroactive compounds. The long hydrocarbon chain present in ubiquinone (Q10) was used as a model hydrophobic molecule. First, the HYDPt-1 layer was self-assembled on the GCE (Glassy Carbon Electrode) from a usual solution of $2 \mu \mathrm{g} / \mathrm{mL}$ Tris buffer, pH 7.0. Next, the self-assembly of Q10 was carried out from 
a solution containing $1 \mathrm{mg}$ of Q10 in $1 \mathrm{~mL}$ of DMF (dimethylformamide). The functionalized hydrophobin layers were stable in a wide range of $\mathrm{pH}$, and effectively blocked the oxidation of the electrode substrates and the access of hydrophilic electroactive probes to the electrode surface. Hydrophobins can control the access of compounds from the solution to the electrode surface and therefore the specificity and sensitivity of the electrode is increased (Bilewicz et al., 2001).

\section{Hydrophobins: medical and pharmaceutical applications}

Hydrophobins are interesting for enhancing the biocompatibility of medical implants in order to avoid the rejection of the implants (Hektor and Scholtmeijer, 2005). Low-friction surfaces are required in various biomedical applications (Misra et al., 2006). To reduce the friction of materials, hydrophobins can be used safely. It has been suggested (Wösten, 2001) and later confirmed (Aimanianda et al., 2009) that by covering fungal aerial structures, hydrophobins shield antigens in the cell wall, thereby protecting the fungal structure against the immune system. These observations point out that the use of hydrophobins in medical applications will possibly not elicit immunogenic reactions. As an alternative, polystyrene (PS) and a copolymer of benzoyl-1,4 phenylene and 1,3-phenylene (PBP) were coated with SC3 (Misra et al., 2006). Stable coating with $10-20 \mathrm{~nm}$ thickness of SC3 was obtained on the polymers after spin coating and/or after adsorption of SC3 from an aqueous solution. Analysis of friction at nanometer scales using Lateral Force Microscopy (LFM) shows ultralow relative friction coefficients for hydrophobin-coated surfaces. A reduction in the friction coefficient of $70-80 \%$ was obtained when compared to bare PS, while a 50-60\% reduction was obtained when compared to bare PBP (note that PBP has a lower friction coefficient than PS). The coatings show a constant reduction of friction over a period of several weeks.

Formulation of hydrophobic drugs using hydrophobins is an interesting alternative to traditional methods, since this new formulation is generic and contains only a non-toxic protein as excipient. The simple preparation in combination with the possibility of performing experiments at small scale allows applying the hydrophobin formulations for screening of potential drugcandidates in a high-throughput setup (Akanbi et al., 2010). Furthermore, the self-assembly property of hydrophobins allows them to be used in formulations of water insoluble drugs for oral administration (Valo et al., 2010). The bioavailability of the hydrophobic drugs cyclosporine A and Nifedipine was increased two and six fold, respectively, when adding SC3 to a drug suspension (Akanbi et al., 2010).

Class II hydrophobins have also been used to stimulate cell growth on solid surfaces (Hou et al., 2008). A coating with HFBI was employed to adhere collagen to the hydrophobic surface of PDMS. The layer of HFBI/collagen helps the adhesion and the growth of human embryonic kidney cells. Similarly, growth of neural stem cells was promoted on micro-domains that had been covered with a HFBI/serum protein layer (Li et al., 2009).

\section{Hydrophobins: multiple promising applications}

There are several possible applications of hydrophobins that were not extensively considered so far. Hydrophobins were found to extend the residence time of hair care products and shampoos (Vic, 2003). They can be used to stabilize emulsions in creams and ointments (Wösten et al., 1994). To develop the stability and particle size of suspensions and emulsions, and to conserve the activity of proteins at surface of a liquid or a solid material, the amphipathic hydrophobins can be exploited (Wösten and de Vocht, 2000). The $T$. reesei $\mathrm{HFBI}$ has been expressed on the surface of yeast by fusing it to the cell wall flocculation protein FLOI of Saccharomyces cerevisiae
(Nakari-Setala et al., 2002). The FLOI-HFBI fusion protein was successfully exposed at the yeast cell surface. The binding affinity of the hydrophobin containing yeast onto hydrophobic silicone-based materials was two-fold increased. No improvement in binding onto hydrophilic carriers has been found (Nakari-Setala et al., 2002). Cells can be immobilized on solid surfaces by using hydrophobins which can improve the biocompatibility of implants after screening. In more advanced experiments, the hydrophobins structure can be modified by chemical cross-linking methods or by genetic engineering (Janssen et al., 2002a, b).

\section{Conclusion}

From what we reported above it can be concluded that the extraordinary properties of hydrophobins offer numerous possibilities for applications in science and technology. Excellent applications are possible in domains necessitating a better stabilization of foams. Related to excessive foaming of carbonated solutions, hydrophobins are excellent indicators for the gushing phenomenon, which is really a serious problem for carbonated beverage industries. For the purification of proteins, fusion proteins between hydrophobins and other proteins can be immobilized on solid substrates, and hydrophobins can help in column protein separation techniques. Hydrophobin coating is a possible intermediate step to attach cells, or other types of molecules to hydrophobic surfaces, such as in biosensors. Formulation of hydrophobic drugs using hydrophobins due to the surface properties of these proteins is another interesting topic that is extensively studied nowadays. However, to further improve several industrial applications involving foams and surface coatings, a better understanding of the hydrophobin binding sides at the molecular level is important. Simultaneously methods for large scale isolation and production are needed.

\section{Acknowledgment}

This work is supported by the Hydrophobin Chair granted to the KU-Leuven by the Duvel-Moortgat Brewery, the trappist beer breweries Orval and Chimay and Cargill Malting.

\section{References}

Aimanianda, V., Bayry, J., Bozza, S., Kniemeyer, O., Perruccio, K., Elluru, S.R., Clavaud, C., Paris, S., Brakhage, A.A., Kaveri, S.V., Srini, V.K., Romani, L., Latge, J.P., 2009. Surface hydrophobin prevents immune recognition of airborne fungal spores. Nature 460, 1117-1121.

Akanbi, M.H.J., Post, E., Meter-Arkema, A., Rink, R., Robillard, G.T., Wang, X., Wösten H.A.B., Scholtmeijer, K., 2010. Use of hydrophobins in formulation of water insoluble drugs for oral administration. Colloids and Surfaces B: Biointerfaces 75, 526-531.

Amaha, M., Kitabatake, K., Nakagava, A., Yoshida, J., Harada, T., 1973. Gushing inducers produced by some moulds strains. In: Proceedings of European Brewery Convention, 14th Congress, Salzburg, pp. 381-398.

Armenante, A., 2008. Pleurotus ostreatus hydrophobins: surface active proteins. Dottorato in Scienze Biotecnologiche - XXI ciclo, Indirizzo Biotecnologie Industriali, Università di Napoli Federico II.

Bailey, M.J., Askolin, S., Horhammer, N., Tenkanen, M., Linder, M.B., Penttila, M., Nakari-Setala, T., 2002. Process technological effects of deletion and amplification of hydrophobin I and II in transformants of Trichoderma reesei. Applied Microbiology and Biotechnology 58, 721-727.

Basheva, E.S., Kralchevsky, P.A., Christov, N.C., Danov, K.D., Stoyanov, S.D., Blijdenstein, T.B.J., Kim, H.-J., Pelan, E.G., Lips, A., 2011. Unique properties of bubbles and foam films stabilized by HFBII hydrophobin. Langmuir 27, 2382-2392.

Bell-Pedersen, D., Dunlap, J.C., Loros, J.J., 1996. Distinct cis-acting elements mediate clock, light, and developmental regulation of the Neurospora crassa eas (ccg-2) gene. Molecular and Cellular Biology 16, 513-521.

Bidochka, M.J., de Koning, J., St Leger, R.J., 2001. Analysis of a genomic clone of hydrophobin (ssgA) from the entomopathogenic fungus Metarhizium anisopliae. Mycological Research 105, 360-364.

Bilewicz, R., Witomski, J., van Der, H.D.A., Tagu, D., Palin, B., Rogalska, E., 2001. Modification of electrodes with self-assembled hydrophobin layers. Journal of Physical Chemistry B 105, 9772-9777.

Bordier, C., 1981. Phase separation of integral membrane proteins in Triton X-114 solution. Journal of Biological Chemistry 256, 1604-1607. 
Callegari, A., Cosnier, S., Marcaccio, M., Paolucci, D., Paolucci, F., Georgakilas, V., Tagmatarchis, N., Vazquez, E., Prato, M., 2004. Functionalised single wall carbon nanotubes/polypyrrole composites for the preparation of amperometric glucose biosensors. Journal of Materials Chemistry 14, 807-810.

Chakarova, S.D., Carlson, A.E., 2004. Model study of protein unfolding by interfaces. Physical Review E: Statistical, Nonlinear, and Soft Matter Physics 69, 021907.

Chaplin, M.F., Kennedy, J.F., 1994. Carbohydrate Analysis: A Practical Approach, 2nd ed. IRL Press, London.

Collen, A., Persson, J., Linder, M.B., Nakari-Setala, T., Penttila, M., Tjerneld, F., Sivars, U., 2002a. A novel two-step extraction method with detergent/polymer systems for primary recovery of the fusion protein endoglucanase I-hydrophobin I. Biochimica et Biophysica Acta 1569, 139-150.

Collen, A., Penttila, M., Stalbrand, H., Tjerneld, F., Veide, A., 2002b. Extraction of endoglucanase I (Ce17B) fusion proteins from Trichoderma reesei culture filtrate in a poly(ethylene glycol) phosphate aqueous two-phase system. Journal of Chromatography A 943, 55-62.

Collen, A., Selber, K., Hyytia, T., Persson, P., Nakari-Setala, T., Bailey, M., Fagerstrom, R., Kula, M.R., Penttila, M., Stalbrand, H., Tjerneld, F., 2002c. Primary recovery of a genetically engineered Trichoderma reesei endoglucanase I (Cel 7B) fusion protein in cloud-point extraction systems. Biotechnology and Bioengineering $78,385-394$

Cooper, A., Kennedy, M.W., 2010. Biofoams and natural protein surfactants. Biophysical Chemistry 151, 96-104.

Corvis, Y., Walcarius, A., Rink, R., Mrabet, N.T., Rogalska, E., 2005. Preparing catalytic surfaces for sensing applications by immobilizing enzymes via hydrophobin layers. Analytical Chemistry 77, 1622-1630.

Cox, A.R., Aldred, D.L., Russell, A.B., 2009. Exceptional stability of food foams using class II hydrophobin HFBII. Food Hydrocolloids 23, 366-376.

Deckers, S.M., Gebruers, K., Baggerman, G., Lorgouilloux, Y., Delcour, J.A., Michiels, C., Derdelinckx, G., Martens, J., Neven, H., 2010. $\mathrm{CO}_{2}$-hydrophobin structures acting as nanobombs in beer. Brewing Science 63, 54-61.

Ehrenbergerova, J., Belcrediova, N., Pryma, J., Vaculova, K., Newman, C.W., 2006. Effect of cultivar, year grown, and cropping system on the content of tocopherols and tocotrienols in grains of hulled and hulless barley. Plant Foods for Human Nutrition 61, 145-150.

Guzmann, M., Eck, P., Baus, U., 2009. Use of hydrophobins as a phase stabilizer. Patent application publication. Pub. No.: US 2009/0282729.

Hektor, H.J., Scholtmeijer, K., 2005. Hydrophobins: proteins with potential. Current Opinion in Biotechnology 16, 434-439.

Hersel, U., Dahmen, C., Kessler, H., 2003. RGD modified polymers: biomaterials for stimulated cell adhesion and beyond. Biomaterials 24, 4385-4415.

Hippeli, S., Elstner, E.F., 2002. Are hydrophobins and/or non-specific lipid transfer proteins responsible for gushing in beer? New hypotheses on the chemical nature of gushing inducing factors. Zeitschrift für Naturforschung C 57, 1-8.

Hou, S., Li, X., Feng, X.Z., Wang, R., Wang, C., Yu, L., Qiao, M.Q., 2009. Surface modification using a novel type I hydrophobin HGFI. Analytical and Bioanalytical Chemistry 394, 783-789.

Hou, S., Yang, K., Qin, M., Feng, X.Z., Guan, L., Yang, Y., Wang, C., 2008. Patterning of cells on functionalized poly(dimethylsiloxane) surface prepared by hydrophobin and collagen modification. Biosensors and Bioelectronics 24 912-916.

Janssen, M.I., Gerssen, B., de Vocht, M.L., van Leeuwen, B.M., van Kooten, T.G., Wösten, H.A.B., Wessels, J.G.H., Scholtmeijer, K., 2002a. Surface modifications created by using engineered hydrophobins. Applied and Environmental Microbiology 68, 1367-1373.

Janssen, M.I., van Leeuwen, M.B., van Kooten, T.G., de Vries, J., Dijkhuizen, L., Wösten, H.A.B., 2004. Promotion of fibroblast activity by coating with hydrophobins in the $\beta$-sheet end state. Biomaterials 25, 2731-2739.

Janssen, M.I., van Leeuwen, M.B.M., Scholtmeijer, K., van Kooten, T.G., Dijkhuizen, L., Wösten, H.A.B., 2002b. Coating with genetic engineered hydrophobin promotes growth of fibroblasts on a hydrophobic solid. Biomaterials 23, 4847-4854.

Joensuu, J.J., Conley, A.J., Lienemann, M., Brandle, J.E., Linder, M.B., Menassa, R., 2010. Hydrophobin fusions for high-level transient protein expression and purification in Nicotiana benthamiana. Plant Physiology 152, 622-633.

Jood, S., Singh, M., 2001. Amino acid composition and biological evaluation of the protein quality of high lysine barley genotypes. Plant Foods for Human Nutrition $56,145-155$.

Kershaw, M.J., Talbot, N.J., 1998. Hydrophobins and repellents: proteins with fundamental roles in fungal morphogenesis. Fungal Genetics and Biology 23, 18-33.

Kisko, K., 2008. Characterization of hydrophobin proteins at interfaces and in solutions using $\mathrm{X}$ rays. Academic dissertation, University of Helsinki, $40 \mathrm{pp}$.

Kleemola, T., Nakari-Setala, T., Linder, M.B., Penttila, M., Kotaviita, E., Olkku, J., Haikara, A., 2001. Characterisation and detection of the gushing factors produced by fungi. In: Proceedings of the 28th European Brewery Convention Congress, Budapest, pp. 1-10.

Lahtinen, T., Linder, M.B., Nakari-Setala, T., Oker-Blom, C., 2008. Hydrophobin (HFBI): a potential fusion partner for one-step purification of recombinant proteins from insect cells. Protein Expression and Purification 59, 18-24.

St Leger, R.J., Staples, R.C., Roberts, D.W., 1992. Cloning and regulatory analysis of starvation-stress gene, $s s g A$, encoding a hydrophobin-like protein from the entomopathogenic fungus, Metarhizium anisopliae. Gene 120,119-124.

Li, X., Hou, S., Feng, X., Yu, Y., Ma, J., Li, L., 2009. Patterning of neural stem cells on poly(lactic-coglycolic acid) film modified by hydrophobin. Colloids and Surfaces B 74, 370-374.

Linder, M.B., 2009a. Hydrophobins: proteins that self-assemble at interfaces. Current Opinion in Colloid and Interface Science 14, 356-363.
Linder, M.B., Qiao, M., Laumen, F., Selber, K., Hyytia, T., Nakari-Setala, T. Penttila, M.E., 2004. Efficient purification of recombinant proteins using hydrophobins as tags in surfactant-based two-phase systems. Biochemistry 43 , $11873-11882$.

Linder, M.B., Szilvay, G.R., Nakari-Setalaa, T., Penttila, M.E., 2005. Hydrophobins: the protein-amphiphiles of filamentous fungi. FEMS Microbiology Review 29, 877-896.

Linder, M.B., 2009b. Hydrophobins: proteins that self-assemble at interface. Current Opinion in Colloid and Interface Science 14, 356-363.

Linder, M.B., Szilvay, G.R., Nakari-Setala, T., Soderlund, H., Penttila, M., 2002. Surface adhesion of fusion proteins containing the hydrophobins HFBI and HFBII from Trichoderma reesei. Protein Science 11, 2257-2266.

Linder, M.B., Selber, K., Nakari-Setala, T., Qiao, M., Kula, M.R., Penttila, M., 2001 The hydrophobins HFBI and HFBII from Trichoderma reesei showing efficient interactions with nonionic surfactants in aqueous two-phase systems. Biomacromolecules 2, 511-517.

Lumsdon, S.O., Green, J., Stieglitz, B., 2005. Adsorption of hydrophobin proteins a hydrophobic and hydrophilic interfaces. Colloids and Surfaces B 44, 172-178.

Mackay, J.P., Jacqueline, K., Matthews, M., Winefield, R.D., Mackay, L.G., Haverkamp R.G., Templeton, M.D., 2001. The hydrophobin EAS is largely unstructured in solution and functions by forming amyloid-like structures. Structure 9, 83-91.

Misra, R., Li, J., Cannon, G.C., Morgan, S.E., 2006. Nanoscale reduction in surface friction of polymer surfaces modified with SC3 hydrophobin from Schizophyllum commune. Biomacromolecules 7, 1463-1470.

Murray, B.S., Dickinson, E., Wang, Y., 2009. Bubble stability in the presence of oil-inwater emulsion droplets: influence of surface shear versus dilatational rheology. Food Hydrocolloids 23, 1198-1208.

Murray, B.S., 2007. Stabilisation of bubbles and foams. Current Opinion in Colloid and Interface Science 12, 232-241.

Nakari-Setala, T., Azeredo, J., Henriques, M., Oliveira, R., Teixeira, J., Linder, M.B. Penttila, M., 2002. Expression of a fungal hydrophobin in the Saccharomyces cerevisiae cell wall: effect on cell surface properties and immobilization. Applied and Environment Microbiology 68, 3385-3391.

Palomo, J.M., Penas, M.M., Fernandez-Lorente, G., Mateo, C., Pisabarro, A.G. Fernandez-Lafuente, R., Ramirez, L., Guisan, J.M., 2003. Solid-phase handling of hydrophobins: immobilized hydrophobins as a new tool to study lipases. Biomacromolecules 4, 204-210.

Parta, M., Chang, Y., Rulong, S., Pinto-DaSilva, P., Kwon-Chung, K.J., 1994. HYP1, a hydrophobin gene from Aspergillus fumigatus, complements the rodletless phenotype in Aspergillus nidulans. Infection and Immunity 62, 4389-4395.

Qin, M., Wang, L.K., Feng, X.Z., Yang, Y.L., Wang, R., Wang, C., Yu, L., Shao, B., Qiao, M.Q., 2007a. Bioactive surface modification of mica and poly(dimethylsiloxane) with hydrophobins for protein immobilization. Langmuir 23, 4465-4471.

Qin, M., Hou, S., Wang, L., Feng, X., Wang, R., Yang, Y., Wang, C., Yu, L., Shao, B., Qiao, M., 2007b. Two methods for glass surface modification and their application in protein immobilization. Colloids and Surfaces B: Biointerfaces 60, 243-249.

Rillig, M.C., 2005. A connection between fungal hydrophobins and soil water repellency? Pedobiologia 49, 395-399.

Sarlin, T., Nakari-Setala, T., Linder, M.B., Penttila, M., Haikara, A., 2005. Fungal hydrophobins as predictors of the gushing activity of malt. Journal of the Institute of Brewing 111, 105-111.

Sarlin, T., Vilpola, A., Kotaviita, E., Olkku, J., Haikara, A., 2007. Fungal hydrophobins in the barley-to-beer chain. Journal of the Institute of Brewing 113, 147-153.

Schmoll, M., Seibel, C., Kotlowski, C., Wollert, F., Vendt, G., Liebmann, B., Kubicek, C.P., 2010. Recombinant production of an Aspergillus nidulans class I hydrophobin (DewA) in Hypocrea jecorina (Trichoderma reesei) is promoter-dependent. Applied Microbiology and Biotechnology 88, 95-103.

Scholtmeijer, K., Wessels, J.G.H., Wösten, H.A.B., 2001. Fungal hydrophobins in medical and technical applications. Applied Microbiology and Biotechnology 56 $1-8$.

Scholtmeijer, K., Janssen, M.I., Gerssen, B., de Vocht, M.L., van Leeuwen, B.M.M., van Kooten, T.G., Wösten, H.A.B., Wessels, J.G.H., 2002. Surface modifications created by using engineered hydrophobins. Applied and Environment Microbiology 68, 1367-1373.

Sehgal, A.S., Kawatra, A., 1998. Reduction of polyphenol and phytic acid content of pearl millet grains by malting and blanching. Plant Foods for Human Nutrition 53, 93-98.

Selber, K., Tjerneld, F., Collen, A., Hyytia, T., Nakari-Setala, T., Bailey, M., Fagerstrom, R., Kand, J., van der Laan, J., Penttila, M., Kula, M.R., 2004. Large-scale separation and production of engineered proteins, designed for facilitated recovery in detergent-based aqueous two-phase extraction systems. Process Biochemistry 39, 889-896.

Shokribousjein, Z., Deckers, S.M., Gebruers, K., Lorgouilloux, Y., Baggerman, G., Verachtert, H., Delcour, J.A., Etienne, P., Rock, J.M., Michiels, C., Derdelinckx, G., 2011. Review: hydrophobins, beer foaming and gushing. Cerevisia 35, 85-101.

Tchuenbou-Magaia, F.L., Norton, I.T., Cox, P.W., 2009. Hydrophobins stabilised airfilled emulsions for the food industry. Food Hydrocolloids 23, 1877-1885.

de Stefano, L., Rea, I., Armenante, A., Giardina, P., Giocondo, M., Rendina, I., 2007. Self-assembled biofilm of hydrophobins protects the silicon surface in the $\mathrm{KOH}$ wet etch process. Langmuir 23, 7920-7922.

Stevenson, P., 2010. Inter-bubble gas diffusion in liquid foam. Current Opinion in Colloid and Interface Science 15, 374-381.

Stubner, M., Lutterschmid, G., Vogel, R.F., Niessen, L., 2010. Heterologous expression of the Hydrophobin FcHyd5p from Fusarium culmorum in Pichia pastoris and evaluation of its surface activity and contribution to gushing of carbonated beverages. International Journal of Food Microbiology 141, 110-115. 
Subkowski, T., Karos, M., Subkowski, T., 2007. Industrial performance proteins: hydrophobin-learning from nature. Journal of Biotechnology 131, 212-213.

Talbot, N.J., Kershaw, M., Wakley, G.E., de Vries, O.M.H., Wessels, J.G.H., Hamer, J.E. 1996. MPG1 encodes a fungal hydrophobin involved in surface interactions during infection-related development of Magnaporthe grisea. Plant Cell 8, 985-999.

Talbot, N.J., Howard, R.J., Gow, N.A.R., 2001. Fungal hydrophobins in the mycota: a comprehensive treatise on fungi as experimental systems for basic and applied research. In: Biology of the Fungal Cell. Springer-Verlag GmbH \& Co, Berlin, Germany, pp. 145-159.

Thomas, D., 1995. Nanotechnology's many disciplines. Biotechnology 13, 439-443.

Valo, H.K., Laaksonen, P.H., Peltonen, L.J., Linder, M.B., Hirvonen, J.T., Laaksonen, T.J., 2010. Multifunctional hydrophobin: toward functional coatings for drug nanoparticles. ACS Nano 4, 1750-1758.

Vic, G., 2003. Cosmetic use of at least one hydrophobin for treating keratin materials, and compositions used. US patent application 2003/0217419.

Wang, X., Permentier, H.P., Rink, R., Kruijtzer, J.A.W., Liskamp, R.M.J., Wösten, H.A.B., Poolman, B., Robillard, G.T., 2004. Probing the self-assembly and the accompanying structural changes of hydrophobin SC3 on a hydrophobic surface by mass spectrometry. Biophysical Journal 87, 1919-1928.

Wang, X., Wang, H., Huang, Y., Zhao, Z., Qin, X., Wang, Y., Miao, Z., Chena, Q., Qiao, M., 2010a. Noncovalently functionalized multi-wall carbon nanotubes in aqueous solution using the hydrophobin HFBI and their electroanalytical application. Biosensors and Bioelectronics 26, 1104-1108.

Wang, X., 2004. Insight into the Interfacial Self-assembly and structural Changes of Hydrophobins. Department of Biochemistry, University of Groningen, Groningen, p. 153.

Wang, Z., Wang, Y., Huang, Y., Li, S., Feng, S., Xu, H., Qiao, M., 2010b. Characterization and application of hydrophobin-dispersed multi-walled carbon nanotubes. Carbon 48, 2890-2898.

Wang, Z., Wang, Z., Feng, S., Xub, H., Zhao, Q., Wang, S., Fang, J., Qiao, M., Kong, D., Zhang, M., 2011. Immobilization of anti-CD31 antibody on electrospun $\operatorname{poly}(\varepsilon$-caprolactone $)$ scaffolds through hydrophobins for specific adhesion of endothelial cells. Colloids and Surfaces B 85, 32-39.

Wang, Z., Lienemann, M., Qiao, M., Linder, M.B., 2010c. Mechanisms of protein adhesion on surface films of hydrophobin. Langmuir 26, 8491-8496.

Wessels, J.G.H., 1993. Fruiting in higher fungi. Advances in Microbial Physiology 34, 147-201.

Wessels, J.G.H., 2000. Hydrophobins, unique fungal proteins. Mycologist 14, 153-159.

Winterburn, J.B, Russell, A.B., Martin, P.J., 2011a. Integrated recirculating foam fractionation for the continuous recovery of biosurfactant from fermenters. Biochemical Engineering Journal 54, 132-139.

Winterburn, J.B., Russell, A.B., Martin, P.J., 2011b. Characterisation of HFBII biosurfactant production and foam fractionation with and without antifoaming agents. Applied Microbiology and Biotechnology 90, 911-920.

Wösten, H.A.B., Wessels, J.G.H., 1997. Review: hydrophobins, from molecular structure to multiple functions in fungal development. Mycoscience 38 363-374.

Wösten, H.A.B, Schuren, F.H.J., Wessels, J.G.H., 1994. Interfacial self-assembly of a hydrophobin into an amphipathic protein membrane mediates fungal attachment to hydrophobic surfaces. The EMBO Journal 13, 5848-5854.

Wösten, H.A.B., 2001. Hydrophobins: multipurpose proteins. Annual Review of Microbiology 55, 625-646.

Wösten, H.A.B., de Vocht, M.L., 2000. Hydrophobins, the fungal coat unraveled. Biochimica et Biophysica Acta 1469, 79-86.

Zapf, M.W., Theisen, S. Vogel, R.F. Niessen, L. 2006. Cloning of wheat ltp1500 and two Fusarium culmorum hydrophobins in Saccharomyces cerevisiae and assessment of their gushing inducing potential in experimental wort fermentation. Journal of the Institute of Brewing 112, 237-245.

Zhao, Z.X., Qiao, M.Q., Yin, F., Shao, B., Wu, B.Y., Wang, Y.Y., 2007. Amperometric glucose biosensor based on self-assembly hydrophobin with high efficiency of enzyme utilization. Biosensors and Bioelectronics 22, 3021-3027. 